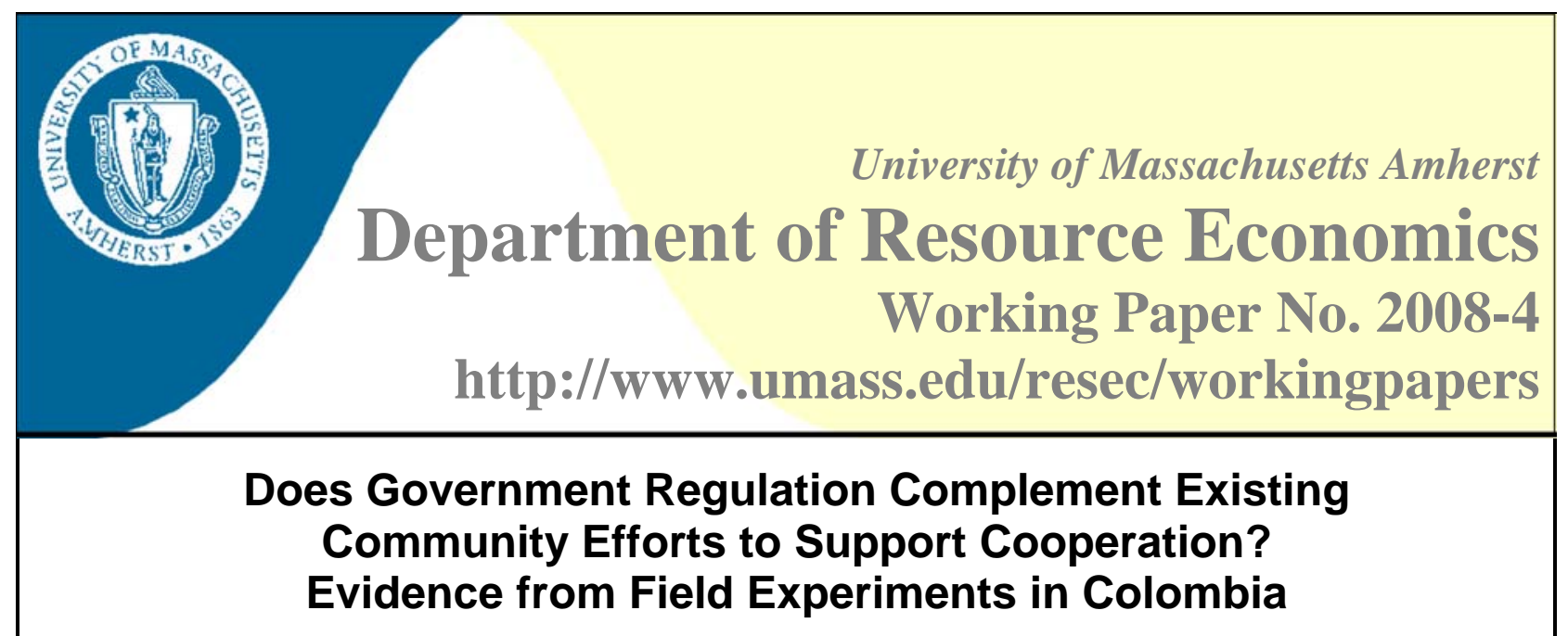

Maria Claudia Lopez ${ }^{1}$, James J. Murphy ${ }^{2}$, John M. Spraggon ${ }^{3,}$, and John K. Stranlund ${ }^{4}$

\begin{abstract}
:
In this paper we describe a field experiment conducted among mollusk harvesters in a community on the Pacific Coast of Colombia. The experiment is based on a standard linear public good and consists of two stages. In the first stage we compare the ability of monetary and nonmonetary sanctions among community members to increase contributions to the public good. In the second stage we add a government regulation with either a high or low sanction for noncompliance to community enforcement efforts. The results for the first stage are consistent with other comparisons of monetary and nonmonetary sanctions within groups; both led to higher contributions. The results from the second stage reveal that government regulations always complemented community enforcement efforts. While the subjects tended to reduce their sanctioning efforts under the government regulations, contributions and earnings were significantly higher than without government interventions. In fact, the combination of community and government enforcement efforts generated near-perfect contributions to the public good. However, more research into the combined roles of government intervention and community enforcement efforts is needed because the complementarity we find may be situation-specific.
\end{abstract}

Keywords: field experiments, public goods, government regulation, community enforcement

JEL Classification: C93, H41, Q2

\footnotetext{
${ }^{1}$ Maria Claudia Lopez, Workshop in Political Theory and Policy Analysis Indiana University, 513 N. Park Avenue, Bloomington, IN 47408-3895

E: mclopezperez@gmail.com P: 413-687-3687 F: 812-855-3150

${ }^{2}$ James Murphy, Department of Economics

University of Alaska Anchorage, 201-D Rasmuson Hall

3211 Providence Drive, Anchorage, AK 99508

E: murphy@uaa.alaska.edu P: 907-786-1936 F: 907-786-4115

${ }^{3}$ John M. Spraggon, Department of Resource Economics

University of Massachusetts, 212A Stockbridge Hall

80 Campus Center Way, Amherst, MA 01003-9246

E: jmspragg@resecon.umass.edu P: 413-545-6651 F: 413-545-5853

${ }^{4}$ John K. Stranlund, Department of Resource Economics

University of Massachusetts, 214 Stockbridge Hall

80 Campus Center Way, Amherst, MA 01003-9246

E: stranlund@resecon.umass.edu P: 413-545-6328 F: 413-545-5853
} 


\title{
Does Government Regulation Complement Existing Community Efforts to Support Cooperation? Evidence from Field Experiments in Colombia
}

\author{
MARIA CLAUDIA LOPEZ \\ School of Environmental and Rural Studies \\ Pontificia Universidad Javeriana \\ Bogotá, Colombia \\ JAMES J. MURPHY \\ Department of Economics \\ University of Alaska-Anchorage \\ JOHN M. SPRAGGON \\ Department of Resource Economics \\ University of Massachusetts Amherst \\ JOHN K. STRANLUND \\ Department of Resource Economics \\ University of Massachusetts Amherst
}

\begin{abstract}
Acknowledgments
We are particularly grateful to Maria Alejandra Velez for her help with this research. In addition, the fieldwork benefitted greatly from the efforts of Pablo Ramos, Laura Estevez and Melisa Arboleda, and Diana Maya. The experiments would not have been possible without the assistance of local community leaders on the southern Pacific coast of Colombia who helped the research team develop credibility with community members. We are also indebted to WWFColombia and INCODER (Instituto Colombiano de Desarrollo Rural), the federal agency in charge of regulating fisheries and other natural resources in Colombia, for help coordinating the fieldwork. We also acknowledge the many useful comments we received from the members of the School of Environmental and Rural Studies at Universidad Javeriana, Colombia, and the participants of the Workshop in Political Theory and Policy Analysis at Indiana University. We received valuable suggestions from James Boyce, Samuel Bowles, Elinor Ostrom, James Walker, and particularly Juan Camilo Cardenas. Wendy Varner and Susanne Hale provided valuable administrative support. We assume complete responsibility for the final contents of this paper.
\end{abstract}




\title{
Does Government Regulation Complement Existing Community Efforts to Support Cooperation? Evidence from Field Experiments in Colombia
}

\begin{abstract}
In this paper we describe a field experiment conducted among mollusk harvesters in a community on the Pacific Coast of Columbia. The experiment is based on a standard linear public good and consists of two stages. In the first stage we compare the ability of monetary and nonmonetary sanctions among community members to increase contributions to the public good. In the second stage we add a government regulation with either a high or low sanction for noncompliance to community enforcement efforts. The results for the first stage are consistent with other comparisons of monetary and nonmonetary sanctions within groups; both led to higher contributions. The results from the second stage reveal that government regulations always complemented community enforcement efforts. While the subjects tended to reduce their sanctioning efforts under the government regulations, contributions and earnings were significantly higher than without government interventions. In fact, the combination of community and government enforcement efforts generated near-perfect contributions to the public good. However, more research into the combined roles of government intervention and community enforcement efforts is needed because the complementarity we find may be situation-specific.
\end{abstract}

Keywords: Field experiments, public goods, government regulation, community enforcement JEL Codes: C93, H41, Q2

\section{Introduction}

In 2003, the Consejo Comunitario of Bahia Malaga (a community on the Pacific Coast of Colombia) collectively decided to stop harvesting a mollusk called piangua for three months each year. The idea was promoted by the community leaders and harvesters in order to preserve the piangua upon which community members rely for subsistence. During these months, the community exerted what they called social control to enforce the restriction. Because the Pacific Coast of Colombia is considered a hot spot of biodiversity, the sustainable management of natural resources in the region is a priority for local and federal governments, as well as international agencies. Government agencies decided to observe the harvest restrictions, but not intervene. Instead, the agencies gave the community an opportunity to self-regulate before deciding whether government intervention was warranted.

There is much empirical evidence that many such communities are able to mange local natural resources more effectively than standard economic theory predicts. Many studies show how some communities are able to make commitments to choices that promote their collective 
interests despite incentives to behave in a self-interested manner (e.g., Ostrom 1990; McKean 1992; Baland and Platteau 1996; and Agrawal 2002). Some have suggested that one way in which communities can maintain cooperation is through mutual monitoring and punishment. In fact, several laboratory experimental studies have found that individuals will choose to sanction others even when it is costly for them to do so and the incentive to do so is weak (Yamagishi 1986; Ostrom et al. 1992; Fehr and Gächter 2000; Masclet et al. 2003; Carpenter et al. 2004).

Yet, even when community efforts are effective at discouraging purely self-interested behavior, the resulting levels of cooperation are not necessarily efficient. This raises the question of whether regulatory intervention by an external government agency would successfully complement local efforts to encourage even higher levels of cooperation. When examining the effects of government regulation of local natural resource use in the developing world, it is usually unreasonable to assume that local communities have no formal or informal conservation institutions in place. Therefore, the design and evaluation of the performance of a government intervention must be done in conjunction with the performance of existing community conservation efforts, and with the recognition that these efforts change in response to new regulations.

Since regulatory interventions are costly, they are only justified in places where they will complement existing community institutions. That is, regulatory interventions are effective only if the combination of government and community efforts leads to a more efficient outcome than community efforts alone. In this paper we report the results of a series of framed field experiments conducted on the southern Pacific coast of Colombia in Afro-Colombian communities that live along the rivers of Buenaventura. The inhabitants of this region devote most of their time to extracting natural resources such as wood, fish and other products from the mangrove forest. Our subjects in particular extract the mollusk piangua. The majority of our subjects were female because the harvesting of mollusks is mainly done by women and children. These experiments were designed to address whether the introduction of new government interventions complement individual monitoring and sanctioning within a community. The experiments were based on a standard linear public goods game, but were described to the participants in terms of contributions of effort to clean the mangroves. ${ }^{1}$

\footnotetext{
${ }^{1}$ We share the concerns of Levitt and List (2007) and others that laboratory experiments with university students playing abstract games may not produce outcomes that are valid predictors of real world behavior. Using the
} 
Each experiment consisted of 20 rounds divided evenly into two stages. In the first stage, individuals played a public goods game with the possibility of sanctioning others in their group. In one set of experiments, individuals paid to send only a signal of displeasure, while in the other, individuals paid to have the payoffs of another reduced by a particular amount. These treatments are similar to those of Fehr and Gächter 2000, Masclet et al. 2003, and Carpenter et al. 2004. ${ }^{2}$ In the second stage of each experiment we added a government requirement that each individual contribute all their tokens to the group projects, and backed this up with random monitoring to check for compliance and a unit fine for violations of the standard. We varied the fine and the order in which the government and the individuals carried out their enforcement activities.

The same processes that make community enforcement efforts effective in the absence of regulatory controls may also serve to complement, and be complemented by, government regulations. Community efforts can support a weak government enforcement apparatus by bringing social pressure to bear on individuals to achieve more efficient outcomes. Moreover, because individuals in a community are likely to have better information about the behavior of their neighbors than the government, individual efforts can help to fine tune government enforcement efforts (Bowles and Gintis 2002). A new government regulation can complement existing community efforts if it provides a signal of efficient individual behavior that can serve as a focal point for community interactions. Also, in communities in which individuals cannot impose a financial sanction on others, but instead must rely on social disapproval, gossip, or public shaming to promote pro-social behavior, regulatory enforcement provides an explicit sanction for noncompliance that can support non-monetary sanctions within communities. ${ }^{3}$

We also recognize that government regulations can substitute for, or crowd out, community efforts to promote more efficient choices. It is possible that community members may transfer enough of the enforcement responsibilities to the government such that overall

taxonomy of Harrison and List (2004), our experiments are framed field experiments. Our experiment closely mirrors the natural occurring dilemma that concerns us, and our subject pool was drawn from populations in which mollusk harvesting in the local mangroves is the main economic activity.

${ }^{2}$ Noussair and Tucker (2005) conducted a treatment in which monetary and the non-monetary sanctions were simultaneously available to their subjects. They found that the combination of monetary and non-monetary individual sanctions led to higher public good contributions and welfare than either type of sanction alone. ${ }^{3}$ Moreover, Thibault and Walker (1976), Tyler (1990), and Frey and Jegen (2001) all suggest that government interventions can be complementary if individuals view them as fair, respectful of their desires, and supportive of their own efforts. 
enforcement is weaker. There are, in fact, many examples of government interventions destroying the capacity of communities to regulate themselves (Frey and Jegen 2001; Bowles 2005). Ostrom (2000) argues that government regulations can crowd-out endogenous cooperative behavior within communities (also see Cardenas et al. 2000). With the same motivation as ours to examine whether government regulations and informal community efforts are complements or substitutes in promoting more efficient behavior, Velez et al. (forthcoming) conducted a series of common pool experiments in three fishing areas of Colombia in which subjects were allowed to communicate with each other under a government regulation to limit their harvest choices. They found that regulations sometimes complemented group communication, they sometimes led to worse outcomes than simple communication, and in other instances they had no impact on informal group efforts to conserve their resource.

In contrast, our results are unequivocal. Like other authors, in the absence of regulatory control we find that individuals make substantial use of the ability to sanction others in their group and contribute more to the public good than is typically observed, even though their dominant Nash strategy would be to contribute nothing and to sanction no one. To the main point of our work, government regulations always complemented community enforcement efforts. While the subjects tended to reduce their sanctioning efforts under the government regulations, contributions and earnings were significantly higher than without the government interventions. In fact, the combination of community and government enforcement efforts generated nearperfect contributions to the public good.

\section{Experimental design}

Table 1 summarizes our experimental design. All treatments were extensions of a standard linear public goods game with $n=5$ subjects per group and an initial endowment of $y_{i}=25$ tokens. Each subject had the option of contributing $g_{i}$ to a group project and keeping the remainder, $y_{i}-g_{i}$, for herself. Contributions to the group project were multiplied by $a=2$ and then divided evenly among all group members; the resulting marginal per capita return is $a / n=0.4$. These parameters were constant in all treatments. Subjects remained in the same group throughout each experiment. 
At the start of the experiment, the experimenter read the instructions aloud. ${ }^{4}$ The instructions did not use a neutral frame; instead, the experiments were described as a group of fishermen contributing effort to clean the mangroves. The instructions were initially written in English and translated into Spanish. To minimize translation errors, the instructions were then translated back into English by another individual. Participants with reading and/or writing difficulties received additional assistance, but they were required to make their decisions on their own. Subjects were seated facing away from each other and were not permitted to communicate amongst themselves.

Subjects were informed that the session would consist of a pair of stages, each of which would last for ten rounds. Instructions for each stage were read at the beginning of the stage. In the first stage, subjects participated in one of two treatments that allowed for community sanctions. For each round, after all subjects made their decisions about how much to contribute to the group project, individual contributions were publicly posted on a board in random order with no personally identifying information to preserve anonymity. ${ }^{5}$ Subjects were then given an opportunity to sanction one other group member by indicating which of the contribution decisions on the board they would sanction. All group members simultaneously made their sanctioning decisions in private. Sending a sanction cost the sender 3 tokens, and each subject could send only one sanction. The impact on the recipient distinguished the pair of stage one treatments. In the Monetary Sanction treatment (M), those who were punished had five tokens subtracted from earnings. In the Social Sanction treatment (S), the punishment was nonmonetary. Similar to Carpenter et al. (2004), instead of having earnings reduced, recipients in the nonmonetary Social Sanction treatment received a picture of an unhappy face: $:$. Whereas in Carpenter et al. (2004) subjects were only allowed to express displeasure to the group as a whole, in our experiments sanctions were directed at a particular individual. In both the Monetary and Social Sanction treatments, since an individual was allowed to sanction only one other person in each round, a subject could receive up to four sanctions in a round. The identity of both the sender and the recipient was kept anonymous.

\footnotetext{
${ }^{4}$ Instructions are available at http://faculty.cbpp.uaa.alaska.edu/jmurphy/research.html. <attached as a reviewers' appendix>

${ }^{5}$ At the start of each round, each subject was given a card with one of the following five letters: V, W, X, Y, Z. This letter was his or his identifier for that particular round only; each round, subjects received a new card. Each individual's contribution decision was posted on the board next to his or her letter for that round. In this way, subjects could identify their own decisions on the board. The sequence of letters for each individual was determined randomly before any experiments were conducted. All treatments used the same sequence.
} 
With this design for stage one, a risk-neutral payoff-maximizing subject would choose contributions to the group account to maximize $\pi_{i}=\left(y_{i}-g_{i}+\frac{a}{n} \sum_{i=1}^{n} g_{i}\right)-\left(3 k_{i}+\alpha \sum_{j \neq i} l_{i j}\right)$, where $k_{i}$ is a binary variable that equals one if player $i$ chose to sanction another player, $\alpha$ equals five in the Monetary Sanction treatments and zero with Social Sanctions, and $l_{i j}$ is a binary variable that equals one if player $i$ received a sanction from player $j$. In the absence of any sanctioning mechanisms, a standard linear public goods game such as this creates a social dilemma because social welfare is maximized when individuals contribute fully to the group project, yet the individual's dominant strategy is to contribute nothing. As Fehr and Gächter (2000) have noted, use of the sanctioning mechanism itself provides a second-order public good. Therefore, at least conceptually, adding either the monetary or social sanctioning should have no effect on outcomes: the dominant strategy remains no contributions to the group account and no investment in sanctioning. Of course, it has been well-established that mean contributions are typically non-zero in standard linear public goods games (Ledyard 1995; Zelmer 2003) and individuals will often choose to sanction others even when it is costly to do so and there is no potential for material gain in future rounds (Yamagishi 1986; Ostrom et al. 1992; Fehr and Gächter 2000; Masclet et al. 2003).

In the second stage, an exogenous external government regulation was combined with the existing community sanctioning mechanism from the previous stage. The government regulation consisted of: (1) a requirement that each individual contribute all tokens to the group project, (2) a per-unit penalty for violations, and (3) a random audit of one group member each round. In the treatments with the Low Penalty (L), those audited and found to be in violation of the regulation were fined one token for each token not invested in the group project. With the High Penalty $(\mathrm{H})$, the fine was four tokens.

With both community efforts and government regulation in effect during stage two, the order in which these were presented could affect individual choices. In particular, if subjects see that another individual's noncooperative behavior is sanctioned by the government, then they might be less likely to impose costly sanctions on this same individual. Therefore we varied the order in which the individual and government enforcement efforts occurred. For half of the eight treatments in Table 1, after the contribution decisions were posted on the board, subjects were given the opportunity to sanction another subject in exactly the same way as in stage one. After 
these sanctioning decisions, one of the five group members was selected for an audit, and this person's decision was also identified on the board with the group contributions. ${ }^{6}$ In the remaining four treatments in Table 1, the order was reversed: first the results of government enforcement were announced, then subjects were given an opportunity to sanction others.

In theory, with a probability, $p=0.20$, of being audited, the per-unit fine, $s=1$, in the Low Penalty treatments should have no effect on the dominant strategy to contribute nothing and to sanction no one. However, when the per-unit penalty is increased to $s=4$ in the High Penalty treatment, the expected marginal penalty is high enough to induce full contributions. In these treatments, the individual will maximize his or her expected payoff $\pi_{i}=y_{i}-g_{i}+\frac{a}{n} \sum_{i=1}^{n} g_{i}-\left(3 k_{i}+\alpha \sum_{j \neq i} l_{i j}\right)-p s\left(y_{i}-g_{i}\right)$,

subject to the constraints $g_{i} \geq 0$ and $g_{i} \leq y_{i}$. The resulting expected marginal payoff is $\partial \pi_{i} / \partial g_{i}=-1+p s+a / n$, with the solution:

$$
g_{i}=\left\{\begin{array}{l}
y_{i} \text { if } p s>1-a / n \\
0 \text { if } p s<1-a / n
\end{array}\right.
$$

In both the Low and High Penalty treatments, the marginal value of violating the requirement to contribute all of one's tokens was $1-a / n=0.6$. The expected marginal penalty in the Low Penalty treatment was $p s=0.2$, therefore, a risk neutral subject's dominant Nash strategy under this treatment was contribute zero tokens $\left(g_{i}=0\right)$ to the group project. On the other hand, with the High Penalty, $p s=0.8$ which implies that a risk neutral subject's dominant strategy was to fully comply with the regulation and contribute all of his or her tokens to the group project $\left(g_{i}=25\right)$. Under both the Low Penalty and High Penalty, there was no incentive for individual to sanction others. Nash predictions about contributions and sanctions hold regardless of the order in which individual and government enforcement occur.

A total of 240 individuals participated in 48 sessions conducted in Buenaventura, Colombia during the summer of 2005. Subjects were recruited from the community with the assistance of a local nongovernmental organization. The subject pool was predominantly female (88\%) with an average age of 34 and an average of 2.7 years of schooling. Harvesting piangua

\footnotetext{
${ }^{6}$ To decide who was going to be audited, the experimenter randomly selected a card from a bag containing one card for each of the five group members. The result of the audit was public; this means that the remaining four group members knew the true identity of the person audited and how much this person was contributing into the group project.
} 
is typically done by women and is the primary activity for $82 \%$ of the participants. The experiment lasted about four hours. There was no show-up payment, but local transportation expenses were covered, and a complimentary snack was provided. At the experiment, earnings were converted to cash at an exchange rate of 20 tokens per peso. Individual earnings ranged between 12,500 and 20,560 pesos with an average of 16,996 pesos (about US\$7.29). ${ }^{7}$

\section{Results}

\section{Stage One}

We begin the analysis by examining the differences between the two community effort treatments in the first stage of the experiment and comparing our results to other studies of monetary and nonmonetary sanctions. By establishing that our stage one results are consistent with others in this literature, we can be confident that any changes in outcomes in stage two are due to treatment effects rather than a fundamental difference with our sample. The experiments created a panel data set with 240 unique subjects participating in a 20-round experiment, for a total of 4800 observations, or 2400 observations in the first stage. Table 2 shows that in stage one, average contributions to the group project with monetary sanctions $(M)$ in the first three rounds average 15.4 tokens (62\% of the initial endowment), increasing by 1.2 tokens to 16.6 (66\%) in rounds 8-10. This is roughly consistent with contributions reported in Masclet et al. (2003). In their monetary sanction treatments with partners, average contributions are about half of the initial endowment with an upward trend over time.

Contributions are consistently about one token lower with nonmonetary social sanctions (S) which is also similar to Masclet et al. (2003) who report a difference between the two treatments of about 2 tokens (out of a 20-token endowment vs. 1 of 25 in our experiments). To test whether this small difference is statistically significant, we estimated the following random effects tobit model using stage one data only (rounds $t=1, \ldots, 10$ ):

$$
g_{i t}=\beta_{0}+\beta_{1} M_{i}+\beta_{2} \text { Round }_{i} \times S_{i}+\beta_{3} \text { Round }_{i} \times M_{i}+\beta_{4} \text { Age }_{i}+\beta_{5} \text { Education }_{i}+v_{i}+\varepsilon_{i t}
$$

Contributions to the group project, $g_{i}$, from individual $i=1, \ldots, 240$ are constrained to lie between 0 and 25 tokens, inclusive. The individual random effects are $v_{i} \sim N\left(0, \sigma_{v}^{2}\right)$ and $\varepsilon_{i t} \sim N\left(0, \sigma_{\varepsilon}^{2}\right)$ is the idiosyncratic error term. To allow for the possibility that decisions vary over time for each

\footnotetext{
${ }^{7}$ A day’s wage in the fishing industry or in agriculture in Buenaventura in 2005 was about 15,000 pesos.
} 
treatment and that these effects may differ across treatments, we interacted round with each of the stage one treatments ( $M$ and $S$ ). Age and education are measured in years. The intercept, $\beta_{0}$, is interpreted as the average individual contribution in the social sanction treatment. Results are presented in Table 3.

The coefficient for the monetary sanction treatment $\left(\beta_{1}=1.60\right)$ is statistically significant, confirming that there is a slightly higher level of contributions when sanctions are monetary. Although contributions are increasing over time in both treatments $\left(\beta_{2}>0\right.$ and $\left.\beta_{3}>0\right)$, this difference is constant throughout all 10 rounds of stage one: a Wald test of the hypothesis that $\beta_{2}$ $=\beta_{3}$ cannot be rejected $\left(\chi^{2}(1)=0.33, p=0.57\right)$. That contributions increase over time is consistent with the results of Fehr and Gächter (2000) who also find that contributions rise, rather than decline as is typical in a public goods experiment without communication or sanctioning (Ledyard 1995). The high levels of cooperation found in these two treatments are similar to the results found in other experiments that allow subjects to punish non-cooperators at a cost to themselves (Fehr and Gächter, 2000; Carpenter et al. 2004; Masclet et al. 2003).

Figure 1 shows that the source of this small difference in average contributions between the two treatments appears to be primarily due to the greater frequency with which subjects fully contribute to the group project with monetary sanctions. The figure presents the distribution of group contributions for each treatment. The first five pairs of bars aggregate contributions into five token intervals, i.e., $g_{i} \in[0,4], \ldots, g_{i} \in[20,24]$. The last pair of bars on the chart include only full contributions $\left(g_{i}=25\right)$. Pure free-riding $\left(g_{i}=0\right)$ is almost nonexistent in both treatments with 14 out of 1200 observations (1.2\%) with monetary sanctions, and 11 out of 1200 (0.9\%) with social sanctions, and a Fisher Exact test confirms that there is no statistically significant difference between these. For each of the first four intervals, which include contributions between 0 and 19 tokens, although the frequency for the social sanctions is slightly higher in each case, Fisher Exact tests again indicate that none these differences are significant. Instead, the differences between treatments are manifested at the higher contribution levels where there are significantly more full contributions with monetary sanctions than social sanctions, and there are more "almost full" contributions, $g_{i} \in[20,24]$, with social sanctions. Hence, this small increase in average contributions appears to be largely driven by a shift from "almost full" to full 
contributions when sanctions are monetary; contributions at the lower end of the distribution are largely unaffected.

Although individual contributions to the group project are higher with monetary sanctions, Table 2 shows that the average earnings in both stage one treatments are almost identical. In the monetary sanction treatment, earnings initially averaged 38.8 (which is $78 \%$ of the maximum possible earnings), increasing to 40.2 in the later rounds. Earnings with social sanctions are essentially the same, beginning at 38.4 and increasing to 40.2 . We estimate a random effects tobit model similar to equation [1] with the dependent variable as earnings, $\pi_{i t} \in[0,50]$, instead of contributions. The estimation results in Table 3 support the conclusion that earnings in both stage one treatments are statistically indistinguishable $\left(\beta_{1}\right.$ is not statistically significant). As with individual contributions, earnings in both treatments increase over time at the same rate. ${ }^{8}$ Masclet et al. (2003) report a similar result. The reason that higher individual contributions with monetary sanctions failed to yield higher earnings is straightforward: although sending a sanction cost the same in both treatments, the monetary penalty incurred by the recipient yielded a financial loss, whereas the social sanction was nonmonetary.

Table 2 also provides a comparison of the use of the sanctioning mechanisms in stage one. During the first three rounds, the frequency with which a sanction was sent is about the same in both treatments (20.3\% with social sanctions and $19.4 \%$ for monetary sanctions). However, whereas sanctioning frequency remains almost constant with the monetary sanction, there is a decline in the use of social sanctions. Half the subjects in each treatment used the sanctioning mechanism at least once. This is slightly higher than that reported in Carpenter et al. (2004) who observed that one-third of subjects in Bangkok and a quarter of Vietnamese subjects used the sanctioning mechanism at least once. The cost of sanctioning the entire group collectively in their experiments was only $2 \%$ of the individual's endowment, whereas in our experiments sanctioning another individual cost $12 \%$ of the 25 -unit initial endowment.

\section{Stage Two}

Having established that the stage one results are consistent with those reported in other studies, we now investigate the possibility of complementarities between the community sanctioning mechanisms in the first stage of the experiment and the formal government regulation

\footnotetext{
${ }^{8}$ We cannot reject the hypothesis that $\beta_{2}=\beta_{3}$ (Wald $\chi^{2}(1)=1.10, p=0.29$ )
} 
implemented in the second stage. Table 4 summarizes the average individual contributions to the group project, average earnings and the frequency with which the sanctioning mechanism was used for stage two. In all treatments, the combination of community sanctions with formal government regulations led to nearly perfect contributions to the group project. There was only one treatment (low penalty regulation, then social sanction, $S / L+S$ ) in which mean contributions were below 20 tokens ( $80 \%$ of the initial endowment). This increase in contributions in all treatments from stage one to stage two provides strong initial evidence in support of the hypothesis that community sanctions and formal government regulations are complements for this sample.

Table 5 presents the estimation results from a random effects tobit model similar to that presented in equation [1], but expanded to include both stage one and stage two data. The model also includes the interaction of the stage two treatments with round. As before, we estimate this model twice, once with individual group contributions, $g_{i} \in[0,25]$, as the dependent variable, and again with individual earnings, $\pi_{i} \in[0,50]$. The estimation results support the conclusion that for all eight treatments, the second stage average contribution levels increased considerably in all treatments relative to the first stage: the four coefficients $\left(\beta_{2}-\beta_{5}\right)$ for the nonmonetary social sanction treatment (S) are all positive and statistically significant. A similar pattern holds with monetary sanctions. Wald $\chi^{2}$ tests confirm what visual inspection of the coefficients in Table 5 suggest: for each pairwise comparison of a stage two treatment $\left(\beta_{6}-\beta_{9}\right)$ with stage one $\left(\beta_{1}\right)$ the differences are positive and highly significant. Moreover, although the interactions of round with stage one social and monetary sanction treatments $\left(\beta_{10}\right.$ and $\left.\beta_{11}\right)$ are positive and significant, the effects over time in stage one are not large enough to yield predicted contributions that equal or exceeds the stage two contributions. Thus we conclude that there are complementarities between community punishment systems and government regulations. This result is consistent with both Bowles (2005) and Frey and Jegen (2001) who suggest that when the community perceives that government regulations may enhance existing cooperation, the two mechanisms may be mutually reinforcing.

Although it is possible that the near-perfect contribution levels are entirely attributable to the introduction of formal regulations, regardless of whether community sanctions are present, we doubt this is likely. In another set of experiments conducted in a different region of Colombia with the same parameters but only external regulations (both high and low), Lopez et 
al. (2007) do not find the contribution levels to be as high as those reported in this paper. Similarly, Neither Cardenas (2005) nor Velez et al. (forthcoming) observe near-perfect cooperation in their common pool resource experiments, including experiments conducted in the same region as our study. Therefore it seems more likely that the high contributions are due to the combined effects of community sanctions and government regulation.

The higher contributions in stage two do not necessarily imply that subjects are better off. Because our experiments include multiple sources of potential earnings reductions-the cost of sanctioning others, the costs of sanctions received when sanctions are monetary, and the cost of fines for violating the government regulations - it is unclear a priori whether the higher stage two contribution levels will lead to improved earnings for subjects. It turns out that in our experiments, community sanctions and government fines were rarely incurred and therefore resulted in minimal earnings losses. Net earnings, after deducting these costs, are generally about 95 percent of gross earnings. Hence, this low incidence of sanctions and penalties, combined with high rates of group contributions lead to statistically higher earnings in stage two compared to stage one. The results for the individual earnings regression in table 5 show that all of the coefficients for the second stage treatments $\left(\beta_{2}-\beta_{9}\right)$ are positive and significant. As is the case for contributions the coefficients on the interaction of round with the stage one social and monetary sanction treatments ( $\beta_{10}$ and $\beta_{11}$ ) are positive and significant but the effect over time is not large enough to yield predicted earnings that equal or exceed stage two earnings. Thus we also observe complementarities between community punishment systems and government regulation in earnings. In our experiment earnings are equivalent to efficiency and so we conclude that the combination of community and government efforts lead to more efficient outcomes than community efforts alone.

In seven of the eight stage two treatments, use of the sanctioning mechanism was lower than in stage one. One possible explanation is that subjects shifted the enforcement burden to the external regulator, essentially a crowding-out problem. On the other hand, it is also possible that the combined threat of community sanctions and government fines was sufficient to induce nearperfect compliance, thereby making social sanctions unnecessary. We can explore these competing hypotheses by looking at whether the order in which the community sanctions and government regulations were implemented. In half of the stage two treatments, subjects first made their sanctioning choices and then one individual was randomly selected for compliance 
with the regulation. In the other four treatments, the order was reversed. If subjects are reducing their sanctioning efforts in response to the presence of government regulations, then we would expect to see a lower frequency of sanctions when the random audits are conducted and results made public prior to the sanctioning decision. To test for possible ordering effects on sanctions we estimated the following random effects logit model:

$$
\begin{gathered}
\text { ReceivedSanction }_{i t}=\beta_{0}+\text { Stage }_{i t} \times\left(\begin{array}{l}
\beta_{1} M_{i t}+\beta_{2} \text { LowContribution }_{i t}+\beta_{3} \text { RegFirst }_{i t} \\
+\beta_{4} \text { RegFirst }_{i t} \times \text { LowContribution }_{i t}
\end{array}\right) \\
\text { Stage }_{i t} \times\left(\begin{array}{l}
\beta_{5} M_{i t}+\beta_{6} \text { LowContribution }_{i t}+\beta_{7} \text { RegFirst }_{i t} \\
+\beta_{8} \text { RegFirst }_{i t} \times \text { LowContribution }_{i t}
\end{array}\right)+v_{i}+\varepsilon_{i t}
\end{gathered}
$$

where ReceivedSanction is a binary variable that equals one if a subject received a community sanction from another group member, Stage1 and Stage2 are dummy variables that equal one for the first and second stages respectively, $M$ equals one for the four treatments that entailed monetary sanctions (includes both stages), RegFirst equals one for the four treatments in which the regulation preceded the community sanctions, ${ }^{9}$ and LowContribution equals one if contributions to the group project are less than $20 .{ }^{10}$ The constant is interpreted as a high contribution, $g_{i} \in[20,25]$, in the two treatments with social sanctions that preceded the random audits. $^{11}$ The results are presented in Table 6.

As a check for consistency among treatments, we test whether the sequencing of government audits and community sanctions in stage two has any effect on stage one behavior. It should not since the first stage was identical, and the results support this: neither $\beta_{3}$ nor $\beta_{4}$ are significant. Whether the community sanction includes a monetary cost for the recipient also has no effect on sanctioning choices (neither $\beta_{1}$ nor $\beta_{5}$ are significant). Although nearly a quarter of the subjects who received sanctions were high contributors who invested at least 20 tokens in the group project (8\% invested all 25 tokens), in both stages low contributors are more likely to be sanctioned (both $\beta_{2}$ and $\beta_{6}$ are positive and significant). The frequency of sanctions in stage two is lower than stage one, but low contributors in the second stage are more likely to be sanctioned

\footnotetext{
${ }^{9}$ These treatments are $\mathrm{M} / \mathrm{H}+\mathrm{M}, \mathrm{M} / \mathrm{L}+\mathrm{M}, \mathrm{S} / \mathrm{H}+\mathrm{S}, \mathrm{S} / \mathrm{L}+\mathrm{S}$

10 Results are robust to any definition of Low Contribution greater than 18 . When a Low Contribution is defined as 18 or less, this threshold is below the average for any second stage treatment so it is not surprising that differences in the results emerge.

11 These treatments are S/S+H and S/S+L.
} 
$(p=0.00)$. We conjecture that because so many subjects are fully contributing in the second stage, there is less tolerance of low contributions.

There is some evidence of an ordering effect ( $\beta_{8}$ is negative and significant). In stage two, when the random audits are conducted prior to community sanctions, low contributors are less likely to receive a sanction from their peers than when the order is reversed. This would be consistent with using community sanctions less frequently to "fill in the gaps" from the random audits. We emphasize that this does not necessarily imply crowding out because it is possible that subjects refrain from sanctioning low contributions when they know the audit outcomes to avoid excessive punishments.

\section{Conclusion}

Vincent Ostrom (1997) suggests that instead of a centralized governance system it is better to build “sustainable democratic systems for sustainable resource use.” A potential first step in developing such systems is to understand complementarities between community sanctioning systems and government regulations. We find complementarities between these enforcements systems for the management of natural resources in a controlled field experiment. Bowles (2005) and Frey and Jegen (2001) argue that these complementarities appear when the internal institutions and their benefits are socially shared by the community. Ostrom (2000) suggests that individuals need to feel that the norm is fair and transparent and users must trust the person implementing the rule. In our experiments, the first stage was the scenario where the participants learned about the benefits of the cooperation. When the government regulation was introduced, its additional enforcement mechanism was supportive of the cooperation already established among users.

Our environment is consistent with Ostrom's (2000) suggestion that rates of compliance increase when individuals feel that others are also following the rules. In our experiment not only were the total group contributions announced in public, but also the individual contributions were reported on a board. This means that the participants were perfectly aware of other's behavior (only the contributions were listed without any information linking the decisions to individual group members). This is also supportive of the Bowles and Gintis 2002 contention 
that when community members have better information about the behavior of their neighbors than the government they can fine tune government enforcement efforts.

However, we are aware that more research is needed because complementarities may be case-specific. Velez et al. (forthcoming) conducted common pool resources experiments in three different regions of Colombia to investigate complementarities between nonbinding communication and formal government regulations. Their experiments did not include the social sanctioning mechanisms in our study. They found that complementarities were present in some, but not all, communities. Their results from the Pacific region (the same region where the experiments presented in this paper were conducted) showed that formal government regulations complemented community efforts to preserve the resource (in this case a communication treatment among group members). They suggest that these complementarities might be due to the strong positive working relationship between environmental regulators and a well-organized group of community members. 


\section{References}

Agrawal Arun. 2002. “Common Resources and Institutional Sustainability.” In The Drama of the Commons. Edited by Elinor Ostrom, Thomas Dietz, Nives Dolsak, Paul C. Stern, Susan Stonich, and Elke U. Weber. Washington, DC: National Academy Press.

Baland, Jean-Marie and Jean-Philippe Platteau. 1996. Halting Degradation of Natural Resources: Is there a Role for Rural Communities? New York: Oxford University Press.

Bowles, Samuel. 2005. "Social Preferences and Public Policy: Are Good Laws a Substitute for Good Citizens?” Santa Fe Institute and University of Siena. http://www.santafe.edu/events/workshops/images/0/0b/Bowles_social_pref_and_public_pol_ \%28paper_july_2005\%29.pdf.

Bowles, Samuel and Herbert Gintis. 2002. “Social Capital and Community Governance.” Economic Journal, 112(483), 419-436.

Cardenas, Juan Camilo. 2005. "Groups, Commons and Regulations: Experiments with Villagers and Students in Colombia". In Psychology, Rationality and Economic Behaviour: Challenging Standard Assumptions. Edited by Bina Agarwal and Alessandro Vercelli. New York: Palgrave Macmillan.

Cardenas, Juan Camilo, John K. Stranlund and Cleve E. Willis. 2000. "Environmental Control and Institutional Crowding-out.” World Development, 28(10), 1719-1733.

Carpenter, Jeffrey, Amrita G. Daniere and Lois M. Takahashi. 2004. “Cooperation, Trust and Social Capital in Southeast Asian Urban Slums.” Journal of Economic Behavior and Organization, 55(4), 533-551

Fehr, Ernst and Simon Gächter. 2000. "Cooperation and Punishment in Public Goods Experiments.” American Economic Review, 90(4), 980-994.

Frey, Bruno and Reto Jegen. 2001. Motivation crowding Theory: A survey of Empirical Evidence, Journal of Economic Surveys, 15(5), 589-611.

Harrison, Glenn W. and John List. 2004. "Field Experiments.” Journal of Economic Literature. 42(4), 1009-1055.

Ledyard, John. 1995. Public goods: A Survey of Experimental Research. In The Handbook of Experimental Economics. Edited by John H. Kagel and Alvin E. Rot. Princeton, NJ: Princeton University Press.

Levitt, Steven D. and John A. List. 2007. "What Do Laboratory Experiments Measuring Social Preferences tell us about the Real World?” Journal of Economic Perspectives, 21(2), 153174. 
Lopez Maria Claudia, John Stranlund, James Murphy and John Spraggon 2007. Comparing the Effectiveness of External Regulation and Social Emotions to Enhance Cooperation: Experimental Evidence from the Field. Unpublished working paper. Amherst, MA: Department of Resource Economics. University of Massachusetts Amherst.

Masclet David, Noussair Charles, Tucker Steven and Villeval Marie-Clairen. 2003. "Monetary and Nonmonetary Punishment in the Voluntary Contributions Mechanism.” American Economic Review, 93(1), 366-379.

McKean, E.A. 1992. "Success on the Commons: A Comparative Examination of Institutions for Common Property Resource Management.” Journal of Theoretical Politics. 4, 247-282.

Noussair, Charles and Steven Tucker. 2005. "Combining Monetary and Social Sanctions to Promote Cooperation.” Economic Inquiry, 43(3), 649-660

Ostrom, Elinor. 1990. Governing the Commons: The Evolution of Institutions for Collective Action. New York: Cambridge University Press.

Ostrom Elinor. 2000. “Crowding Out Citizenship.” Scandinavian Political Studies. 23(1), 3- 16.

Ostrom, Elinor, James Walker and Roy Gardner. 1992. "Covenants with and without a Sword: Self-governance is Possible.” American Political Science Review. 86(2), 404-417.

Ostrom, Vincent. 1997. The Meaning of Democracy and Vulnerability of Democracies: A Response to Tocqueville's Challenge. Ann Arbor, MI: University of Michigan Press.

Thibault, John and Laurens Walker. 1976. Procedural Justice: A Psychological Analysis. Hillsade, NJ: Erlbaum.

Tyler, Tom. 1990. Why People Obey the Law: Procedural Justice, Legitimacy and Compliance. New Haven, CT: Yale University Press.

Velez, Maria Alejandra, James J. Murphy and John K. Stranlund. Forthcoming. “Centralized and Decentralized Management of Local Common Resources in the Developing World: Experimental Evidence from Fishing Communities in Colombia.” Economic Inquiry.

Yamagishi, Toshio. 1986. “The Provision of a Sanctioning System as a Public Good.” Journal of Personality and Social Psychology. 51(1), 110-116.

Zelmer Jennifer. 2003. “Linear Public Goods Experiments: A Meta-Analysis.” Experimental Economics. 6(3), 299-310. 
Table 1. Experimental Design

\begin{tabular}{|c|c|c|}
\hline $\begin{array}{c}\text { Stage } 1 \\
\text { Community Sanctions } \\
\text { (Rounds 1-10) }\end{array}$ & $\begin{array}{c}\text { Stage } 2 \\
\text { Community Sanctions and } \\
\text { Government Regulation (order varies) } \\
\text { (Rounds 11-20) }\end{array}$ & Treatment ID \\
\hline \multirow[t]{4}{*}{$\begin{array}{l}\text { Social Sanction only } \\
\qquad(\mathrm{S} /)\end{array}$} & $\begin{array}{l}\text { Social Sanction }(S) \text {, then } \\
\text { Low Penalty regulation }(+\mathrm{L})\end{array}$ & $\mathrm{S} / \mathrm{S}+\mathrm{L}$ \\
\hline & $\begin{array}{l}\text { Social Sanction }(S) \text {, then } \\
\text { High Penalty regulation }(+\mathrm{L})\end{array}$ & $\mathrm{S} / \mathrm{S}+\mathrm{H}$ \\
\hline & $\begin{array}{l}\text { Low Penalty regulation }(\mathrm{L}) \text {, then } \\
\text { Social Sanction }(+\mathrm{S})\end{array}$ & $\mathrm{S} / \mathrm{L}+\mathrm{S}$ \\
\hline & $\begin{array}{l}\text { High Penalty regulation }(\mathrm{H}) \text {, then } \\
\text { Social Sanction }(+\mathrm{S})\end{array}$ & $\mathrm{S} / \mathrm{H}+\mathrm{S}$ \\
\hline \multirow[t]{4}{*}{$\begin{array}{l}\text { Monetary Sanction only } \\
\text { (M/) }\end{array}$} & $\begin{array}{l}\text { Monetary Sanction }(\mathrm{M}) \text {, then } \\
\text { Low Penalty regulation }(+\mathrm{L})\end{array}$ & $\mathrm{M} / \mathrm{M}+\mathrm{L}$ \\
\hline & $\begin{array}{l}\text { Monetary Sanction }(\mathrm{M}) \text {, then } \\
\text { High Penalty regulation }(+\mathrm{H})\end{array}$ & $\mathrm{M} / \mathrm{M}+\mathrm{H}$ \\
\hline & $\begin{array}{l}\text { Low Penalty regulation }(\mathrm{L}) \text {, then } \\
\text { Monetary Sanction }(+\mathrm{M})\end{array}$ & $\mathrm{M} / \mathrm{L}+\mathrm{M}$ \\
\hline & $\begin{array}{l}\text { High Penalty regulation }(\mathrm{H}) \text {, then } \\
\text { Monetary Sanction }(+\mathrm{M})\end{array}$ & $\mathrm{M} / \mathrm{H}+\mathrm{M}$ \\
\hline
\end{tabular}


Table 2. Contributions, Earnings and Use of Sanctioning Mechanism (Stage 1)

\begin{tabular}{lcccc}
\hline & $\begin{array}{c}\text { Rounds } \\
\mathbf{1} \text { to } \mathbf{3}\end{array}$ & $\begin{array}{c}\text { Rounds } \\
\mathbf{4} \text { to } \mathbf{7}\end{array}$ & $\begin{array}{c}\text { Rounds } \\
\mathbf{8} \text { to 10 }\end{array}$ & $\begin{array}{c}\text { All Rounds } \\
\mathbf{1} \text { to 10 }\end{array}$ \\
\hline Average Contributions & & & & \\
Monetary Sanction (M) & 15.4 & 15.9 & 16.6 & 16.0 \\
& $(0.30)$ & $(0.29)$ & $(0.35)$ & $(0.18)$ \\
Social Sanction (S) & 14.1 & 14.9 & 15.7 & 14.9 \\
& $(0.28)$ & $(0.28)$ & $(0.34)$ & $(0.17)$ \\
Average Earnings & & & & 39.4 \\
Monetary Sanction (M) & 38.8 & 39.3 & 40.2 & $(0.18)$ \\
Social Sanction (S) & $(0.31)$ & $(0.30)$ & $(0.33)$ & 39.3 \\
& 38.4 & 39.3 & 40.2 & $(0.18)$ \\
Percent Use of Sanctioning & $(0.30)$ & $(0.29)$ & $(0.35)$ & $18.2 \%$ \\
Mechanism & & & & $18.3 \%$ \\
Monetary Sanction (M) & & & & \\
\hline Social Sanction (S) & $19.4 \%$ & $19.4 \%$ & $18.3 \%$ & \\
\hline
\end{tabular}

Standard errors in parentheses. 
Table 3:

Random Effects Tobit Model of Individual Contributions and Individual Earnings (Stage 1 only)

\begin{tabular}{lcc}
\hline Variable & $\begin{array}{c}\text { Individual } \\
\text { Contributions } \\
\left(\boldsymbol{g}_{\boldsymbol{i}}\right)\end{array}$ & $\begin{array}{c}\text { Individual } \\
\text { Earnings } \\
\left(\boldsymbol{\pi}_{\mathbf{i}}\right)\end{array}$ \\
\hline Constant $\left(\beta_{0}\right)$ & $13.27 * * *$ & $38.3 * * *$ \\
& $(1.23)$ & $(1.11)$ \\
$\mathrm{M}\left(\beta_{1}\right)$ & $1.60 * *$ & 0.42 \\
& $(0.77)$ & $(0.71)$ \\
Round $\times \mathrm{S}\left(\beta_{2}\right)$ & $0.24 * * *$ & $0.25 * * *$ \\
& $(0.04)$ & $(0.04)$ \\
Round $\times \mathrm{M}\left(\beta_{3}\right)$ & $0.20 * * *$ & $0.18 * * *$ \\
& $(0.05)$ & $(0.05)$ \\
Age $\left(\beta_{4}\right)$ & -0.01 & -0.02 \\
& $(0.03)$ & $(0.02)$ \\
Education $\left(\beta_{5}\right)$ & $0.28 * *$ & 0.09 \\
\hline
\end{tabular}

Estimated using equation [1]. Number of observations 2400. Missing values for age and education replaced with sample means. Standard errors in parentheses. *Significant at $10 \%, * *$ significant at $5 \%$, ***significant at $1 \%$ 
Table 4: Contributions, Earnings and Use of Sanctioning Mechanism (Stage 2)

\begin{tabular}{ccccc}
\hline & Rounds & Rounds & Rounds & All Roun \\
& $\mathbf{1 1}$ to $\mathbf{1 3}$ & $\mathbf{1 4}$ to $\mathbf{1 7}$ & $\mathbf{1 8}$ to $\mathbf{2 0}$ & $\mathbf{1 1}$ to 20 \\
\hline & & & & \\
Average Contributions & & & & \\
$\mathrm{M} / \mathrm{H}+\mathrm{M}$ & 22.4 & 23.2 & 23.6 & 23.1 \\
& $(0.46)$ & $(0.31)$ & $(0.34)$ & $(0.21)$ \\
$\mathrm{M} / \mathrm{L}+\mathrm{M}$ & 23.5 & 23.3 & 23.5 & 23.4 \\
& $(0.38)$ & $(0.37)$ & $(0.40)$ & $(0.22)$ \\
$\mathrm{M} / \mathrm{M}+\mathrm{H}$ & 21.3 & 22.2 & 22.6 & 22.0 \\
& $(0.57)$ & $(0.41)$ & $(0.47)$ & $(0.28)$ \\
$\mathrm{M} / \mathrm{M}+\mathrm{L}$ & 20.4 & 21.5 & 21.9 & 21.3 \\
& $(0.71)$ & $(0.56)$ & $(0.66)$ & $(0.37)$ \\
$\mathrm{S} / \mathrm{H}+\mathrm{S}$ & 23.5 & 23.5 & 23.9 & 23.6 \\
& $(0.35)$ & $(0.32)$ & $(0.37)$ & $(0.20)$ \\
$\mathrm{S} / \mathrm{L}+\mathrm{S}$ & 18.7 & 18.9 & 18.6 & 18.8 \\
& $(0.73)$ & $(0.58)$ & $(0.79)$ & $(0.40)$ \\
$\mathrm{S} / \mathrm{S}+\mathrm{H}$ & 23.3 & 23.6 & 23.7 & 23.6 \\
& $(0.42)$ & $(0.32)$ & $(0.38)$ & $(0.21)$ \\
$\mathrm{S} / \mathrm{S}+\mathrm{L}$ & 22.3 & 23.0 & 23.5 & 22.9 \\
& $(0.49)$ & $(0.39)$ & $(0.40)$ & $(0.25)$
\end{tabular}

\section{Average Earnings}

$\begin{array}{ccccc}\mathrm{M} / \mathrm{H}+\mathrm{M} & 43.4 & 45.5 & 46.5 & 45.2 \\ & (1.08) & (0.75) & (0.85) & (0.51) \\ \mathrm{M} / \mathrm{L}+\mathrm{M} & 47.5 & 47.7 & 47.7 & 47.6 \\ & (0.44) & (0.43) & (0.45) & (0.26) \\ \mathrm{M} / \mathrm{M}+\mathrm{H} & 40.1 & 44.4 & 44.0 & 43.0 \\ & (1.48) & (0.55) & (0.99) & (0.59) \\ \mathrm{M} / \mathrm{M}+\mathrm{L} & 43.9 & 44.8 & 45.5 & 44.7 \\ & (0.74) & (0.58) & (0.67) & (0.38) \\ \mathrm{S} / \mathrm{H}+\mathrm{S} & 46.88 & 47.59 & 47.95 & 47.48 \\ & (0.55) & (0.42) & (0.55) & (0.28)\end{array}$




$\begin{array}{ccccc}\mathrm{S} / \mathrm{L}+\mathrm{S} & 41.59 & 41.93 & 43.23 & 41.92 \\ & (0.82) & (0.66) & (0.85) & (0.44) \\ \mathrm{S} / \mathrm{S}+\mathrm{H} & 46.39 & 47.95 & 48.33 & 47.59 \\ & (0.99) & (0.40) & (0.43) & (0.36) \\ \mathrm{S} / \mathrm{S}+\mathrm{L} & 46.52 & 47.48 & 48.27 & 47.43 \\ & (0.53) & (0.42) & (0.40) & (0.26)\end{array}$

\section{Percent Use of}

Sanctioning Mechanism

\begin{tabular}{lrrrr}
$\mathrm{M} / \mathrm{H}+\mathrm{M}$ & $16.7 \%$ & $9.2 \%$ & $5.6 \%$ & $10.3 \%$ \\
$\mathrm{M} / \mathrm{L}+\mathrm{M}$ & $11.1 \%$ & $6.7 \%$ & $4.4 \%$ & $7.3 \%$ \\
$\mathrm{M} / \mathrm{M}+\mathrm{H}$ & $22.2 \%$ & $22.5 \%$ & $18.9 \%$ & $21.3 \%$ \\
$\mathrm{M} / \mathrm{M}+\mathrm{L}$ & $12.2 \%$ & $10.8 \%$ & $6.7 \%$ & $10.0 \%$ \\
$\mathrm{~S} / \mathrm{H}+\mathrm{S}$ & $7.8 \%$ & $4.2 \%$ & $3.3 \%$ & $5.0 \%$ \\
$\mathrm{~S} / \mathrm{L}+\mathrm{S}$ & $20.0 \%$ & $15.0 \%$ & $14.4 \%$ & $16.3 \%$ \\
$\mathrm{~S} / \mathrm{S}+\mathrm{H}$ & $10.0 \%$ & $11.7 \%$ & $5.6 \%$ & $9.3 \%$ \\
$\mathrm{~S} / \mathrm{S}+\mathrm{L}$ & $8.9 \%$ & $2.5 \%$ & $4.4 \%$ & $5.0 \%$ \\
\hline
\end{tabular}

Standard errors in parenthesis 
Table 5: Random Effects Tobit Model of Individual Contributions, and Individual Earnings

(Stages 1 \& 2 combined)

\begin{tabular}{|c|c|c|c|c|}
\hline \multirow{2}{*}{$\begin{array}{r}\text { Variable } \\
\text { Constant }\left(\beta_{0}\right)\end{array}$} & \multicolumn{2}{|c|}{$\begin{array}{c}\text { Individual } \\
\text { Contributions } \\
\left(g_{i}\right)\end{array}$} & \multicolumn{2}{|c|}{$\begin{array}{c}\text { Individual } \\
\text { Earnings } \\
\left(\pi_{\mathbf{i}}\right)\end{array}$} \\
\hline & $\begin{array}{c}13.07 \\
(1.27)\end{array}$ & $* * *$ & $\begin{array}{l}37.31 \\
(0.96)\end{array}$ & $* * *$ \\
\hline $\mathrm{M}\left(\beta_{1}\right)$ & $\begin{array}{r}1.69 \\
(0.84)\end{array}$ & $* *$ & $\begin{array}{r}0.54 \\
(0.72)\end{array}$ & \\
\hline $\mathrm{S} / \mathrm{H}+\mathrm{S}\left(\beta_{2}\right)$ & $\begin{array}{r}15.30 \\
(1.03)\end{array}$ & $* * *$ & $\begin{array}{r}10.01 \\
(0.93)\end{array}$ & $* * *$ \\
\hline $\mathrm{S} / \mathrm{S}+\mathrm{H}\left(\beta_{3}\right)$ & $\begin{array}{r}14.90 \\
(1.10)\end{array}$ & $* * *$ & $\begin{array}{r}9.94 \\
(0.96)\end{array}$ & $* * *$ \\
\hline $\mathrm{S} / \mathrm{L}+\mathrm{S}\left(\beta_{4}\right)$ & $\begin{array}{r}6.67 \\
(0.89)\end{array}$ & $* * *$ & $\begin{array}{r}3.71 \\
(0.91)\end{array}$ & $* * *$ \\
\hline $\mathrm{S} / \mathrm{S}+\mathrm{L}\left(\beta_{5}\right)$ & $\begin{array}{r}11.02 \\
(1.01)\end{array}$ & $* * *$ & $\begin{array}{r}9.16 \\
(0.97)\end{array}$ & $* * *$ \\
\hline $\mathrm{M} / \mathrm{H}+\mathrm{M}\left(\beta_{6}\right)$ & $\begin{array}{c}12.47 \\
(1.18)\end{array}$ & $* * *$ & $\begin{array}{r}6.62 \\
(1.02)\end{array}$ & $* * *$ \\
\hline $\mathrm{M} / \mathrm{M}+\mathrm{H}\left(\beta_{7}\right)$ & $\begin{array}{r}9.37 \\
(1.17)\end{array}$ & $* * *$ & $\begin{array}{r}2.52 \\
(1.03)\end{array}$ & $* *$ \\
\hline $\mathrm{M} / \mathrm{L}+\mathrm{M}\left(\beta_{8}\right)$ & $\begin{array}{c}14.03 \\
(1.27)\end{array}$ & $* * *$ & $\begin{array}{r}9.00 \\
(1.08)\end{array}$ & $* * *$ \\
\hline $\mathrm{M} / \mathrm{M}+\mathrm{L}\left(\beta_{9}\right)$ & $\begin{array}{r}9.94 \\
(1.15)\end{array}$ & $* * *$ & $\begin{array}{r}6.63 \\
(1.04)\end{array}$ & $* * *$ \\
\hline Round $\times \mathrm{S}\left(\beta_{10}\right)$ & $\begin{array}{r}0.24 \\
(0.06)\end{array}$ & $* * *$ & $\begin{array}{r}0.26 \\
(0.06)\end{array}$ & $* * *$ \\
\hline Round × M $\left(\beta_{11}\right)$ & $\begin{array}{r}0.21 \\
(0.06)\end{array}$ & $* * *$ & $\begin{array}{r}0.18 \\
(0.06)\end{array}$ & $* * *$ \\
\hline Round $\times \mathrm{S} / \mathrm{H}+\mathrm{S}\left(\beta_{12}\right)$ & $\begin{array}{r}0.20 \\
(0.15)\end{array}$ & & $\begin{array}{r}0.20 \\
(0.13)\end{array}$ & \\
\hline Round $\times \mathrm{S} / \mathrm{S}+\mathrm{H}\left(\beta_{13}\right)$ & $\begin{array}{r}0.06 \\
(0.16)\end{array}$ & & $\begin{array}{r}0.13 \\
(0.13)\end{array}$ & \\
\hline Round $\times \mathrm{S} / \mathrm{L}+\mathrm{S}\left(\beta_{14}\right)$ & $\begin{array}{r}0.02 \\
(0.12)\end{array}$ & & $\begin{array}{r}0.14 \\
(0.13)\end{array}$ & \\
\hline Round $\times \mathrm{S} / \mathrm{S}+\mathrm{L}\left(\beta_{15}\right)$ & $\begin{array}{r}0.51 \\
(0.15)\end{array}$ & $* * *$ & $\begin{array}{r}0.33 \\
(0.14)\end{array}$ & $* *$ \\
\hline
\end{tabular}




$\begin{array}{lrlrl} & 0.35 & * * & 0.42 & * * * \\ \text { Round } \times \mathrm{M} / \mathrm{H}+\mathrm{M}\left(\beta_{16}\right) & (0.14) & & (0.13) & \\ & 0.33 & * * & 0.57 & * * * \\ \text { Round } \times \mathrm{M} / \mathrm{M}+\mathrm{H}\left(\beta_{17}\right) & (0.14) & & (0.13) & \\ & 0.21 & & 0.35 & * * \\ \text { Round } \times \mathrm{M} / \mathrm{L}+\mathrm{M}\left(\beta_{18}\right) & (0.16) & & (0.14) & \\ & 0.50 & * * * & 0.33 & * * * \\ \text { Round } \times \mathrm{M} / \mathrm{M}+\mathrm{L}\left(\beta_{19}\right) & (0.14) & & (0.13) & \\ & -0.01 & & 0.01 & \\ \text { Age }\left(\beta_{20}\right) & (0.03) & & (0.02) & \\ & 0.31 & * * & 0.15 & \\ \text { Education }\left(\beta_{21}\right) & (0.13) & & (0.09) & \end{array}$

Number of observations 4800 . Missing values for age and education replaced with sample means. Standard errors in parentheses. *Significant at $10 \%$, **significant at $5 \%$, ***significant at $1 \%$. 
Table 6: Random Effects Logit Model of Sanctions Received (Stages 1 \& 2 combined)

\begin{tabular}{|c|c|c|}
\hline \multirow{2}{*}{$\begin{array}{l}\text { Variable } \\
\text { Constant }\left(\beta_{0}\right)\end{array}$} & \multicolumn{2}{|c|}{$\begin{array}{c}\text { Individual } \\
\text { Contributions } \\
\left(g_{i}\right) \\
\end{array}$} \\
\hline & $\begin{array}{l}-4.08 \\
(0.26)\end{array}$ & $* * *$ \\
\hline Stage1 × M $\left(\beta_{1}\right)$ & $\begin{array}{r}0.29 \\
(0.25)\end{array}$ & \\
\hline Stage $1 \times$ LowContribution $\left(\beta_{2}\right)$ & $\begin{array}{r}2.04 \\
(0.21)\end{array}$ & $* * *$ \\
\hline Stage1 $\times$ RegFirst $\left(\beta_{3}\right)$ & $\begin{array}{c}-0.21 \\
(0.41)\end{array}$ & \\
\hline Stage $1 \times$ LowContribution $\times$ RegFirst $\left(\beta_{4}\right)$ & $\begin{array}{r}0.01 \\
(0.40)\end{array}$ & \\
\hline Stage $2 \times \mathrm{M}\left(\beta_{5}\right)$ & $\begin{array}{r}0.20 \\
(0.27)\end{array}$ & \\
\hline Stage $2 \times$ LowContribution $\left(\beta_{6}\right)$ & $\begin{array}{r}3.18 \\
(0.28)\end{array}$ & $* * *$ \\
\hline Stage2 $\times$ RegFirst $\left(\beta_{7}\right)$ & $\begin{array}{r}0.16 \\
(0.31)\end{array}$ & \\
\hline Stage $\times$ LowContribution $\times$ RegFirst $\left(\beta_{8}\right)$ & $\begin{array}{l}-1.03 \\
(0.41)\end{array}$ & $* *$ \\
\hline
\end{tabular}

Dependent variable equals one if the individual received a sanction, zero otherwise. Number of observations 4800 . Standard errors in parentheses. *Significant at $10 \%$, **significant at $5 \%, * * *$ significant at $1 \%$. 
Figure 1. Distribution of Contributions to Group Project in Stage 1 by Treatment

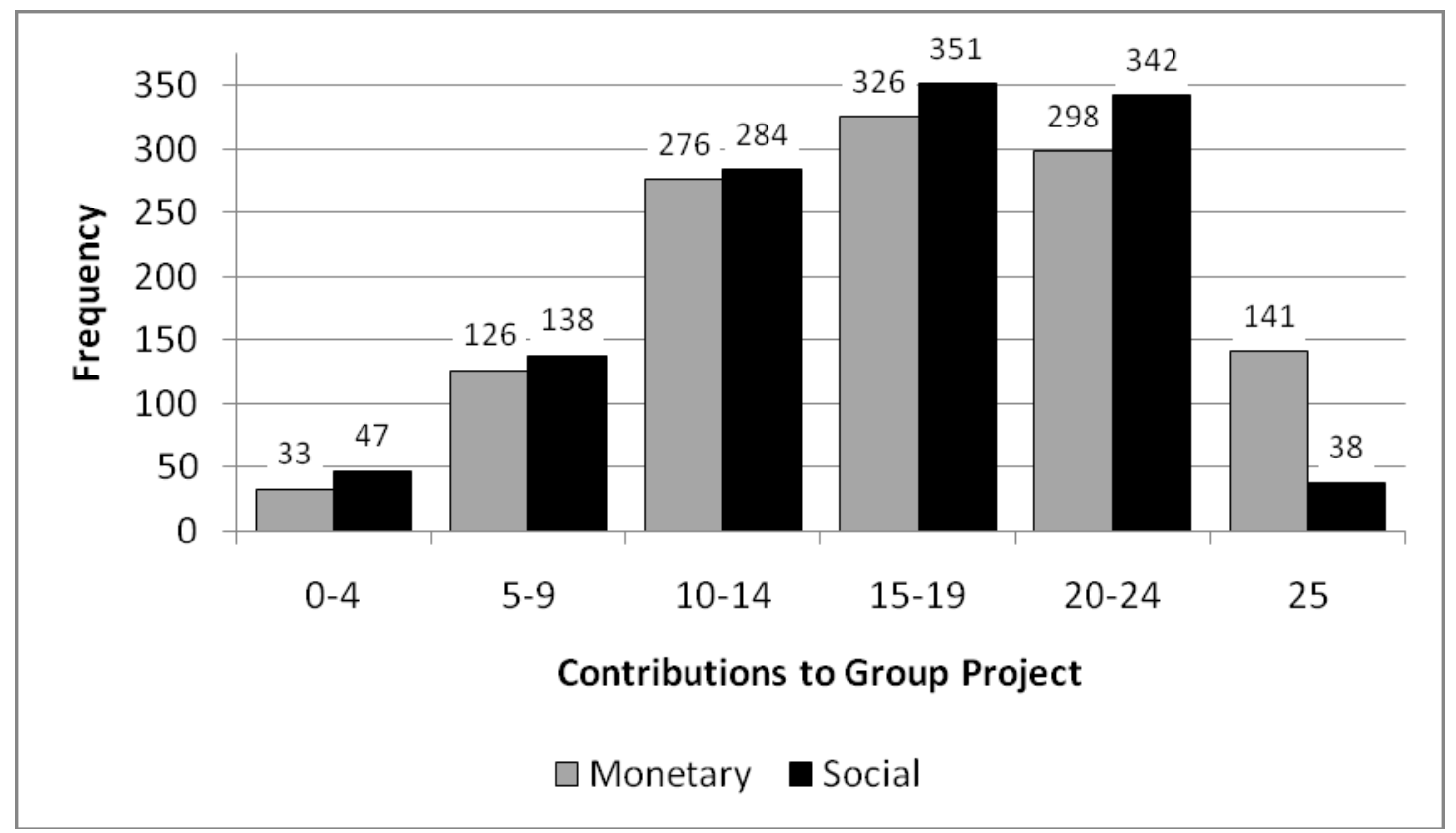




\section{Reviewers’ Appendix - Experiment Instructions}

\section{Consent Form}

You will receive a consent form that you will need to sign before we start the exercise.

$<$ Hand out the consent form $>$

This document is a requirement for Universities conducting research with people. In this consent form, we inform you about the confidentiality and management of the information we kept from you. If you decide to participate, you must sign this sheet, certifying that we have informed you about the project and about the way we will use the information we collect.

The information on this form is confidential, and no one other than the researcher will have access to it. This form is important: it not only ensures the confidentiality of the information you provide, also needed in order to for us to provide you with the money you have earned at the end of the exercise.

$<$ Read the consent form $>$

You are asked to sign the consent form after we are done with instructions.

If you have a question, please raise your hand. 


\section{Introduction}

Before we begin today's exercise, we want to thank everybody for coming and participating. This exercise is part of a project funded by international foundations and by the Universidad Javeriana. The purpose is to understand how people make decisions related to the use of shared natural resources. All the earnings you will make during the exercise, as well as the information you will give us, are strictly confidential. We will not reveal your earnings to any member of the community or to anyone else.

This exercise attempts to recreate a situation in which a group of people must make decisions about how to maintain a shared natural resource for example cleaning the beach. An example could be the time used in maintaining the mangrove in the area where you harvest. Today's exercise may be different from the exercise that other members of your community have already participated in. For that reason, any comments you might have heard about the exercise may not apply to what we are doing here today. Therefore, please make your decisions based on the instructions that we are about to present. Please pay careful attention to these instructions so that you can make good decisions. You will be paid in cash at the end of the exercise based on your decisions and the decisions of others.

Please remain seated and do not communicate with other participants. If you have a question, please raise your hand.

\section{Instructions}

Today`s exercise has two parts, with 10 rounds each. I will explain you now the first part of the exercise. Once we are done with the first 10 rounds, we will explain the second part. After finishing the second part, while you answer a survey, we will calculate your earnings.

You will participate in a group of 5 people. Today there will be groups participating at the same time. However, each group is independent from other groups and the decisions of the other groups do not affect the decisions of your own group. Each group will be differentiated by the color of the sheets used during the exercise.

In this exercise you will earn money depending upon your decisions and the decisions of the other members of your group. The reason why we use money during the exercise is to recreate real life situations where your economic decisions have consequences for your pocket. 
We do not expect that the money you earn will be a payment for your participation in this study or the only reason to participate. You will participate for several rounds that are equivalent, for instance, to days of labor or fishing harvest.

Now we will explain how to participate in the exercise. In order to understand this exercise, think about how you allocate your time. You may spend part of your time doing things that benefit you and your family only. You can also spend another part of your time doing things that help everyone in your community. For example, you might spend part of your time fishing for your family and you, to spend or sell; and you may spend also part of your time cleaning or maintaining the beach or the mangrove, which benefits everyone in the community including you and your family. This exercise is meant to be similar to this sort of situation, in which you must decide between doing something that benefits you only and something that benefits everyone in the community.

During the exercise we shall not speak about pesos but rather about tokens. During this exercise your entire earnings will be calculated in tokens. However we will not use real tokens. Each token will be converted to pesos at the following rate:

$$
1 \text { token }=20 \text { pesos }
$$

At the end of the exercise we will add the total amount of tokens you have earned during all the rounds. We will pay you the equivalent of your tokens earnings in pesos rounded to the nearest $\$ 500$ pesos.

$<$ Examples $>$

The money will be paid to each one of you in cash depending upon your earnings. At the beginning of each round, each participant will receive 25 tokens. With the 25 tokens you must decide how many tokens you want to keep for yourself, and how many tokens you want to contribute to a group project.

At the end of each round, you will have some earnings. Those earnings are the result of two things: 
1) The number of tokens that you keep for yourself.

2) Your share of the tokens from the group project. These tokens are calculated as follows:

The total of tokens contributed to the group by the 5 members (yours and the other 4 members of your group) will be doubled which means multiplied by 2 and then divided evenly among the 5 members of your group. Each group member will receive an equal share regardless of how many tokens he or she contributed to the group project.

For example, suppose the total contribution from all group members is 60 tokens. After we double these 60 tokens, there will be 120 tokens. We will then divide these 120 tokens evenly among the 5 group members, so each person will receive 24 tokens from the group project.

Remember, at the end of the exercise we will add the total amount of tokens earned during the 20 rounds, and for each token we will pay you 20 pesos.

\section{Decision Card}

I will now explain how you will inform us of your decision at each round. In each round you will write down how many tokens you will keep for yourself, and how many tokens you will contribute to the group account in a Decision Card. The Decision cards are these small pieces of papers.

\begin{tabular}{|r|c|}
\hline \multicolumn{2}{|c|}{ DECISION CARD } \\
\hline PARTICIPANT NUMBER: & 2 \\
\hline ROUND NUMBER: & 1 \\
\hline TOKENS I KEEP FOR MYSELF: & \\
\hline TOKENS I CONTRIBUTE TO THE GROUP PROJECT: & \\
\hline
\end{tabular}

As you can see, the Decision Card has a participant number on it. This number will be your identification during the exercise. 
Remember in each round you have 25 tokens, your decision is to choose how many tokens you want to keep for yourself and how many tokens you want to contribute to the group project. Therefore the sum of the "TOKENS I WILL KEEP FOR MYSELF" + "TOKENS I WILL CONTRIBUTE TO THE PROJECT” must be equal to 25.

In each round you will have to write:

- “TOKENS I WILL KEEP FOR MYSELF”: this means, how many tokens you are keeping for yourself (a number between 0 and 25).

- “TOKENS I WILL CONTRIBUTE TO THE PROJECT”: this means, how many tokens you are contributing to the group project (a number between 0 and 25)

Remember, the sum of the “TOKENS I WILL KEEP FOR MYSELF” PLUS “TOKENS I WILL CONTRIBUTE TO THE PROJECT” must be equal to 25.

After all the members of your group have made and written down their decisions we will pick up the participants' cards and calculate the group contribution to the project. We will then announce the total contribution to the project, and each person's share of the earnings from the group project. Please remember that your decisions are private and that you can not show them to the other members of the group. What questions do you have?

\section{Calculation Sheet}

You will receive a Calculation Sheet to keep a record of your decisions and the amount of tokens you earned. The Calculation Sheet we will hand out has an example of how you should fill the Calculation Sheet. Please write down your participant number on the sheet. Your participant number is the same number shown on your Decision Cards.

Let's see how to use the Calculation Sheet by looking at an example all together. Therefore we will suppose that everybody decide to keep the same amount of tokens. Remember: this is just an example to learn how to fill the paper. After this round each one may choose any number. 
Let's see how to use the sheet using the example. At the beginning of each round you will have an endowment of 25 tokens. This number is written in the Column A. With these 25 tokens you will decide how many tokens you want to keep for yourself and how many you will contribute to the project. Remember the amount of tokens you keep for yourself + the amount of tokens you contribute to the project must be equal to 25 .

Suppose that you decided to keep 15 tokens. Hence, you have to write 15 under column B of the Calculation Sheet, “TOKENS I WILL KEEP FOR MYSELF”: as shown in the example below. You should also write this number in on the Decision Card (the small card)

If you decide to keep 15 tokens, then you will contribute 10 tokens (25-15) to the group project. You will write this number in column $\mathrm{C}$ of the Calculation Sheet, “TOKENS I CONTRIBUTE TO THE PROJECT” as shown in the example below. You should also write this number on the Decision Card (the small card).

You are writing the amount you keep for yourself and the amount you contribute to the project in two places, in the Decision Card, and in the Calculation Sheet. Please, check that you have written the same numbers in the two sheets before you hand in the Decision Card.

\begin{tabular}{|c|c|c|c|c|c|c|}
\hline \multirow[t]{2}{*}{1.1 .1} & \multicolumn{2}{|c|}{ CALCULATION SHEET } & \multicolumn{3}{|c|}{ Participant Number: 2} & \multirow[b]{2}{*}{$\mathbf{F}$} \\
\hline & $\mathbf{A}$ & $\mathbf{B}$ & $\mathrm{C}$ & $\mathbf{D}$ & $\mathbf{E}$ & \\
\hline Round & $\begin{array}{c}\text { Starting } \\
\text { Number of } \\
\text { Tokens }\end{array}$ & $\begin{array}{c}\text { Tokens I Keep } \\
\text { for Myself }\end{array}$ & $\begin{array}{c}\text { Tokens I } \\
\text { Contribute to } \\
\text { the project } \\
\text { (= } 25-\mathrm{B})\end{array}$ & \begin{tabular}{|c|} 
TOTAL \\
Tokens \\
Contributed \\
To The Project
\end{tabular} & $\begin{array}{c}\text { Tokens I } \\
\text { Earned } \\
\text { From The } \\
\text { Project }\end{array}$ & $\begin{array}{c}\text { My Earnings in } \\
\text { This Round } \\
(=\mathbf{B}+\mathrm{E})\end{array}$ \\
\hline Example & 25 & 15 & 10 & 50 & 20 & 35 \\
\hline Practice & 25 & & & & & \\
\hline
\end{tabular}

After all the members of the group have finished making their decisions, we will collect the cards of the 5 participants and calculate the "TOTAL TOKENS CONTRIBUTED TO THE PROJECT.” We will announce that number, and you will write that number down in your 
column D. In this case it will be $50(10+10+10+10+10)$. Remember this is only an example, which means that we you will make your decision you can choose any number between 0 and 25 . The double of the 50 tokens is 100 . These 100 tokens will evenly divided among the 5 group members, so each person will receive 20 tokens from the group project, no matter how many tokens he contributed to the project. As you can see in the column E, “TOKENS I EARNED FROM THE PROJECT” you can find the number 20. To calculate you earnings in each round, you must add the number in column B “Tokens I will keep for myself” + the column E “TOKENS I EARNED FROM THE PROJECT.” In this example your earnings will be 15+20 =35. As you can see that number is written down in the column F "my earnings in this round." At the end of exercise, we will add the total amount of tokens earned during the 20 rounds, and for each token earned we will give you 20 pesos.

\section{Practice rounds}

Before we start the exercise we will do some practice rounds. The decisions that you make in these practice rounds will not affect your earnings today. In order to properly understand how the exercise works, we will do the first practice round all together using the same amount of tokens as contribution for the project. Remember that when each one of you makes individual decisions of the tokens I keep for myself and tokens I contribute to the project you can choose the numbers you want as long as they add 25.

Suppose that in this practice round everybody decides to keep 8 tokens to the project. So, please take one of the decisions cards with the word "Practice" written in the number of rounds. Where it says “TOKENS I KEEP FOR YOURSELF” write the number 8. You will write that number also in the column B of your Calculation Sheet.

In this example, each one of you decided to keep 8 tokens, so the tokens each one contribute to the project is 17 (25-8). Please write 17 on the Decision Card and the Calculation Sheet column C, in “TOKENS I CONTRIBUTE TO THE PROJECT.”

After you are done with your decisions, the assistant will calculate the total tokens contributed to the project. In this case, the total amount of tokens contributed to the project is 85. Each of you should now write 85 under column D of the Calculation Sheet "TOTAL TOKENS CONTRIBUTED TO THE PROJECT.” After I double the amount of tokens of contributed to the project, there will be 170 tokens. Then I will divide the 170 tokens among you in equal shares. 
Each one of you will receive 34 tokens. Now please, in column E “TOKENS I EARNED FROM THE PROJECT” of the Calculation Sheet write 34. You can calculate your earnings by adding the column $\mathrm{B}+$ the column E. Your total earnings should be $42(=34+8)$. Write that number in column F "MY EARNINGS IN THIS ROUND.”

Another important thing: all the decisions you will make during the exercise are private, for that reason you need to keep the sheets covered so no one else can see it.

What question do you have?

Before we start the exercise with real money, we are going to add another rule to the exercise. After you are done calculating your earnings, I will write in the blackboard the amount each of you contributed to the project under one of this letters $(\mathrm{V}, \mathrm{W}, \mathrm{X}, \mathrm{Y}, \mathrm{Z})$. I will only reveal the values; you will not be able to know how much any specific person allocated to the group. The order in which I am writing the numbers does not have any relation with the participant number. This means that the contributions of a particular person may show up in a different place each time. You will recognize your contribution to the project from the number in the blackboard, but the others in the group will not know what you did. We will handle additional pieces of paper with a letter $(\mathrm{V}, \mathrm{W}, \mathrm{X}, \mathrm{Y}, \mathrm{Z})$. This means that your contribution in this round is the number that appears under the letter you received.

\section{Calculation Sheet}

As you can see, the Calculation Sheet has an additional column titled "WHAT LETTER AM I IN THIS ROUND.” In this column you will write the letter the assistant will handle to you.

Do you have a question?

Let`s do now another practice round, but this time each person will choose the number she wants. 


\section{STAGE 1}

\section{Internal Punishment with Social Sanction}

Before we begin playing for real money, I would like to point something out.

Once you have seen the contribution that each person in your group did, if you want you can pay 3 tokens to send a displeasure message to someone in your group. The message will be sent in the form of an unhappy face. This unhappy face will let know that person to whom you sent the message that someone is displeased with his contribution to the group. You will be able to choose to whom you want to send the unhappy face according to the individual contributions that the assistant writes in the board at the end of each round.

Each round you will have the right to send one unhappy face only. However, it is possible that you receive more than one unhappy face every round. Every unhappy face you get means that some one in your group paid 3 tokens to send you a message. For example, if you get 3 unhappy faces, you will know that 3 people in your group paid to send you a message. You can get a maximum of 4 unhappy faces per round. In such case, you will know that each of the other 4 group members paid 3 tokens each to send you an unhappy face, but you are not having tokens taken away. We will know if you want to send a message or not because in every round you will have an additional "Send Message” card.

$<$ Hand over the "Send Message" card. The "Send Message" cards will be handed over only we needed round by round $>$

Each round you will decide whether you send someone a message or not. If you do not want to pay the "send message" fee, you will have to fill this card anyway and give it to the assistant. If you do not want to send a message, fill with an $\mathrm{X}$ in the case "I DO NOT WANT TO SEND AN UNHAPPY FACE, THIS COSTS ME 0 TOKENS.”

If you do want to send a message to someone in your group, put an $\mathrm{X}$ in the case "I DO WANT TO SEND AN UNHAPPY FACE, THIS COSTS ME 3 TOKENS” and then put the letter identifying that someone in the case "TO THE PLAYER IDENTIFIED WITH THE LETTER: ” 
The assistant will collect the five "Send Message cards" and will count how many messages each player got. Then, every member will get a note with the number of unhappy faces that the others sent him. If someone did was not sent any message, he will still get a blank note.

Let's suppose that someone was sent two unhappy faces, in this case he will get a note like this <show the note with the two faces>, but if he was not sent anything he will get this note $<$ show the blank note $>$

Please remind that all decisions are private. Therefore you are asked not to show this note nor talk to anyone when you get the "unhappy faces” note.

\section{Calculation Sheet}

I will now give a new Calculation Sheet. <pick up the old ones and hand over the new ones>. As you can see, the Calculation Sheet is very similar to the one we used in the practice rounds, the first columns are identical to what we had already used and there are 4 new columns. These news columns are:

- “I DID SEND AN UNHAPPY FACE CARD”: If you did send a message, then you will have to write “ 3 ” in column $\mathrm{H}$. This because sending a message costs you 3 tokens. If you did not send an unhappy face then you will write " 0 ” in that column.

- “TO WHOM I SEND THE UNHAPPY FACE”, in column I you will put the letter of the player that you sent the message to. If you did not send a message, please write a slash.

Remember that the information regarding “I DID SEND AN UNHAPPY FACE CARD” and “TO WHOM I SEND THE UNHAPPY FACE” must be recorded in the Calculation Sheet and in the "Send Message" card.

Once the assistant has handed to every one the "unhappy face" note, you will be able to fill the remaining columns:

- “NUMBER OF UNHAPPY FACES I GOT”, in column J please write the number of unhappy faces you got in each round. I you got nothing, write “0.”

- “TOKENS I GET AFTER SENDING UNHAPPY FACE MESSAGE”, in column K please write the total amount of tokens you have in each round, after you subtract the 
unhappy face fee. If you did not send anything, please write the same number that you had already written in column F.

Are there any question?

The best way to understand this exercise is with an example. Let's do another practice round again. Please decide how many tokens are you keeping for your self and how many you are putting into the project. <Follow all steps as described $>$.

\section{Internal Punishment System with Monetary Sanction}

Before we begin playing for real money, I would like to point something out. Once you have seen the contribution that each person in your group did, if you want you can pay 3 tokens to take away 5 tokens from someone in your group. We are using this rule to allow the players to send a message of displeasure. You will be able to choose to whom you want to take away 5 tokens according to the individual contributions that the assistant writes in the board at the end of each round.

Each round you will have the right to have 5 tokens taken away. However, it is possible that you be taken away more than 5 tokens every round. Every 5 tokens reduction in your earnings means that some one in your group paid 3 tokens to have 5 tokens taken away from you. For example, if you get 15 tokens deducted from your earnings, you will know that 3 people in your group paid to have those tokens taken away from you.

You can get a maximum of 20 tokens deducted per round. In such case, you will know that each

of the other 4 group members paid 3 tokens each to have those tokens deducted from your account.

We will know if you want to reduce someone else’s earnings because in every round you will have an additional "Reduce Earnings” card.

$<$ Hand over the "Reduce Earnings" card. The "Reduce Earnings" cards will be handed over only we needed round by round>

Each round you will decide whether you reduce someone's earnings or not. If you do not want to pay the "reduce earnings" fee, you will have to fill this card anyway and give it to the 
assistant. If you do not want to send a message, fill with an X in the case "I DO NOT WANT TO REDUCE SOMEONE ELSE EARNINGS, THIS COSTS ME 0 TOKENS.”

If you do want to reduce someone else's earnings, put an X in the case "I DO WANT TO REDUCE SOMEONE ELSE'S EARNINGS, THIS COSTS ME 3 TOKENS” and then put the letter identifying that someone in the case "to the player identified with the letter:"

The assistant will collect the five "reduce earnings" cards and will see how many reductions each player got. Then, every member will get a note with the number of tokens he will be taken away. If someone did not get any reductions, he will still get a blank note.

Let's suppose that someone was sent two "reduce earnings” cards, in this case he will get a note like this <show the note with number "-10" >, but if he was not sent anything he will get this note <show the blank note $>$

Please remind that all decisions are private. Therefore you are asked not to show this note nor talk to anyone when you get the "reduce earnings" note.

\section{Calculation Sheet}

I will now give a new Calculation Sheet. <pick up the old ones and hand over the new ones>. As you can see, the Calculation Sheet is very similar to the one we used in the practice rounds, the first columns are identical to what we had already used and there are 4 new columns.

These news columns are:

- “I DID SEND A REDUCE EARNINGS CARD”: If you did send a reduce earnings card, then you will have to write " 3 ” in column H. This is because having 5 tokens taken away from someone costs you 3 tokens. If you did not send anything then you will write " 0 ” in that column.

- “TO WHOM I SEND THE REDUCE EARNINGS”, in column I you will put the letter of the player that you sent the reduce earnings card to. If you did not send a message, please draw a slash. 
Remember that the information regarding “I DID SEND A REDUCE EARNINGS CARD” and “TO WHOM I SEND THE REDUCE EARNING CARD” must be recorded in the Calculation Sheet and in the "Reduce Earnings" card.

Once the assistant has handed to every one the "Reduce Earnings” note, you will be able to fill the remaining columns:

- “NUMBER OF TOKENS I HAVE MY EARNINGS REDUCED”, in column J please write the number of tokens you were deducted in each round. I you got nothing, write " 0. "

- “TOKENS I GET AFTER SENDING/GETTING THE REDUCE EARNINGS MESSAGE”, in column K please write the total amount of tokens you have in each round, after you subtract the "reduce earning message” fee and the sum of reductions you were sent. If you did not send or get anything, please write the same number that you had already written in column F.

Are there any question?

The best way to understand this exercise is with an example. Let's do another practice round again. Please decide how many tokens are you keeping for your self and how many you are putting into the project. <Follow all steps as described $>$. 


\section{STAGE 2}

\section{Regulation Low Penalties (High) + Internal Punishment with Social Sanction}

We are about to begin the second part of the exercise. This part of the exercise is very similar to the first, the difference being that during the next 10 rounds we are introducing a penalty before the moment when you decide whether sending an unhappy face message or not. The target we seek with the penalty is that every group member contributes all its 25 tokens into the project.

To encourage that every one contributes its 25 tokens into the group project, you will face a penalty of 1 token (4 tokens) for every token you decide to keep for your self.

I will hand to you a table where the penalties levels are shown according to the amount of tokens that you keep for your self or in other words, those tokens that you did not contribute into the project. <Hand over penalties table $>$

You will face a penalty only if you are audited and you are contributing with less than 25 tokens to project. In other words, you can contribute less than 25 tokens, but if you are audited, you will have to pay 1 token (4 tokens) for every token you kept for your self. However, it is very difficult to audit every group member every time. Therefore, immediately after you have calculated your total amount of tokens earned in each round but before you decide whether to send an unhappy face message, we will randomly pick the person to be audited. Once we have determined who will be audited, we will continue with the exercise just as we did on the first part.

To decide who will be audited, we will randomly draw a ballot from a bag containing 5 ballots, once for every group member and respectively labeled.

This implies that in every round, each player has one chance in 5 to be audited. If your ballot is drawn and you contribute less than 25 tokens into the project you will have to pay the penalty. The result of the audit will be public; this means that the remaining 4 group members will know who is audited and how much this person was contributing into the group project.

Only one player will be audited per round. The drawn ballot will be returned to the bag. This means that in every round, all 5 ballots will be in the bag. This is to say that it is possible to be audited more than once during the exercise, just as it is possible that you are never audited. Let's so an example, let's think that everyone kept 15 tokens and put 10 tokens into the project. Total amount of tokens in the group project was 50, therefore “TOKENS IS EARNED FROM 
THE PROJECT” is 20. And just as we had calculated as wrote in the table, “TOTAL AMOUNT OF TOKENS EARNED IN THIS ROUND BEFORE SENDING A MESSAGE AND THE PENALTY” is 35. Since you kept 15 tokens, this is 15 more than what the rule allowed. Hence, if the ballot with your number is picked, you will have to pay 15 tokens (60 tokens). If your number is not picked, you will not have to pay any penalty. $<$ Take a ballot from the bag. Then, show to every body how the audit is publicly done>

After the audit, the exercise will continue just as we have done to this point, that is, every player will decide if a message is to send, and pay the respective fee. Then, the assistant will collect the 'Send Message” cards and individually inform how many messages everyone got.

\section{Calculation Sheet}

$<$ Hand over the Calculation Sheet $>$

To the Calculation Sheet we have used so far, we have added 3 new columns. These 3 columns are located after column F “TOTAL AMOUNT OF TOKENS EARNED IN THIS ROUND.” The new columns are:

- column G: AUDITED THIS ROUND (yes/no). If your number was the one picked in the random ballot draw, you will write yes. If your number was not picked, you will write no.

- column H: PENALTY AMOUNT: you will keep track of the tokens you are penalized with when you are audited. If you are audited and were breaking the rule, the assistant will make public announce of how many tokens you were keeping for your self and the respective penalty. The assistant will personally write this amount in your Calculation Sheet.

If your number was not picked, you don't have to pay any penalty regardless of how many tokens you kept. In this case please fill this column with a slash.

- Column I: AMOUNT OF TOKENS AFTER PENALTY. If you were penalized, you will write down in this column the number corresponding to the amount of tokens you earned (column F) minus the penalty amount.

Let's do a practice round. 


\section{Internal Punishment with Social Sanction + Low/High Penalty Regulation}

We are about to begin the second part of the exercise. This part of the exercise is very similar to the first, the difference being that during the next 10 rounds we are introducing a penalty after the moment when you decide whether sending an unhappy face message or not. The target we seek with the penalty is that every group member contributes all its 25 tokens into the project.

To encourage that every one contributes its 25 tokens into the group project, you will face a penalty of 1 token (4 tokens) for every token you decide to keep for your self.

I will hand to you a table where the penalties levels are shown according to the amount of tokens that you keep for your self or in other words, those tokens that you did not contribute into the project. <hand over penalties table>

You will face a penalty only if you are audited and you are contributing with less than 25 tokens to project. In other words, you can contribute less than 25 tokens, but if you are audited, you will have to pay 1 token (4 tokens) for every token you kept for your self. However, it is very difficult to audit every group member every time. Therefore, after you decided whether you pay the fee to send the unhappy message, after you got those messages sent to you, and after you calculated the total amount of earned tokens, we will randomly pick to person to be audited.

To decide who will be audited, we will randomly draw a ballot from a bag containing 5 ballots, once for every group member and respectively labeled.

This implies that in every round, each player has one chance in 5 to be audited. If your ballot is drawn and you contribute less than 25 tokens into the project you will have to pay the penalty. The result of the audit will be public; this means that the remaining 4 group members will know who is audited and how much this person was contributing into the group project.

Only one player will be audited per round. The drawn ballot will be returned to the bag. This means that in every round, all 5 ballots will be in the bag. This is to say that it is possible to be audited more than once during the exercise, just as it is possible that you are never audited.

Let's do an example, let's think that everyone kept 15 tokens and contributed 10 tokens into the project. The total amount of tokens in the group project was 50, therefore "TOKENS I EARNED FROM THE PROJECT” is 20. And just as we had calculated as wrote in the table, “TOTAL AMOUNT OF TOKENS EARNED IN THIS ROUND BEFORE SENDING A MESSAGE AND THE PENALTY” is 35. Since you kept 15 tokens, this is 15 more than what 
the rule allowed. Hence, if the ballot with your number is picked, you will have to pay 15 tokens (60 tokens). If your number is not picked, you will not have to pay any penalty.

$<$ Take a ballot from the bag. Then, show to every body how the audit is publicly done> Please keep in mind that the ballot drawn will be done only after we are done with the steps as we did in the first part, this is, after every player decides whether to pay or not the "Send Message” fee and after you got those messages sent to you, and after you calculated the total amount of earned tokens.

\section{Calculation Sheet}

$<$ Hand over the Calculation Sheet $>$ To the Calculation Sheet we have used so far, we have added 3 new columns. These 3 columns are located after column K “TOKENS I GET AFTER

SENDING UNHAPPY FACE MESSAGE.” The new columns are:

- Column L: AUDITED THIS ROUND (yes/no). If your number was the one picked in the random ballot draw, you will writ yes. If your number was not picked, you will write no.

- Column M: PENALTY AMOUNT: You will keep track of the tokens you are penalized with when you are audited. If you are audited and were breaking the rule, the assistant will make public announce of how many tokens you were keeping for your self and the respective penalty. The assistant will personally write this amount in your Calculation Sheet.

If your number was not picked, you don't have to pay any penalty regardless of how many tokens you kept. In this case please fill this column with a slash.

- Column N, AMOUNT OF TOKENS AFTER PENALTY. If you were penalized, you will write down in this column the number corresponding to the amount of tokens you earned minus the penalty amount.

Let's do a practice round. 


\section{Low (High) Penalty Regulation + Internal Punishment with Monetary Sanction.}

We are about to begin the second part of the exercise. This part of the exercise is very similar to the first, the difference being that during the next 10 rounds we are introducing a penalty before the moment when you decide whether you pay the fee to have someone else earnings reduced or not. The target we seek with the penalty is that every group member contributes all its 25 tokens into the project.

To encourage that every one contributes its 25 tokens into the group project, you will face a penalty of 1 token (4 tokens) for every token you decide to keep for your self.

I will hand to you a table where the penalties levels are shown according to the amount of tokens that you keep for your self or in other words, those tokens that you did not contribute into the project. <Hand over penalties table>

You will face a penalty only if you are audited and you are contributing with less than 25 tokens to project. In other words, you can contribute less than 25 tokens, but if you are audited, you will have to pay 1 token (4 tokens) for every token you kept for your self. However, it is very difficult to audit every group member every time. Therefore, immediately after you have calculated your total amount of tokens earned in each round but before you decide whether you pay the fee to have someone else earnings reduced, we will randomly pick the person to be audited. Once we have determined who will be audited, we will continue with the exercise just as we did on the first part.

To decide who will be audited, we will randomly draw a ballot from a bag containing 5 ballots, once for every group member and respectively labeled.

This implies that in every round, each player has one chance in 5 to be audited. If your ballot is drawn and you put less than 25 tokens into the project you will have to pay the penalty. The result of the audit will be public; this means that the remaining 4 group members will know who is audited and how much this person was putting into the group project.

Only one player will be audited per round. The drawn ballot will be returned to the bag. This means that that in every round, all 5 ballots will be in the bag. This is to say that it is possible to be audited more than once during the exercise, just as it is possible that you are never audited. 
Let's do an example, let's think that everyone kept 15 tokens and put 10 tokens into the project. Total amount of tokens in the group project was 50, therefore "TOKENS I EARNED FROM THE PROJECT" is 20. And just as we had calculated as wrote in the table, "TOTAL AMOUNT OF TOKENS EARNED IN THIS ROUND BEFORE SENDING A MESSAGE AND THE PENALTY” is 35. Since you kept 15 tokens, this is 15 more than what the rule allowed. Hence, if the ballot with your number is picked, you will have to pay 15 tokens (60 tokens). If your number is not picked, you will not have to pay any penalty.

$<$ Take a ballot from the bag. The, show to every body how the audit is publicly done> After the audit, the exercise will continue just as we have done to this point, that is, every player will decide if he/she wants to pay the 3 tokens fee to deduct someone else earnings by 5 tokens. Then, the assistant will collect the "reduce earnings" cards and individually inform how many reductions everyone got.

\section{Calculation Sheet}

$<$ hand over the Calculation Sheet $>$

To the Calculation Sheet we have used so far, we have added 3 new columns. These 3 columns are located after column F “TOTAL AMOUNT OF TOKENS EARNED IN THIS ROUND.” The new columns are:

- Column G: “AUDITED THIS ROUND (YES/NO).” If your number was the one picked in the random ballot draw, you will write yes. If your number was not picked, you will write no.

- Column H: "PENALTY AMOUNT": You will keep track of the tokens you are penalized with when you are audited. If you are audited and were breaking the rule, the assistant will make public announce of how many tokens you were keeping for your self and the respective penalty. The assistant will personally write this amount in your Calculation Sheet.

If your number was not picked, you don't have to pay any penalty regardless of how many tokens you kept. In this case please fill this column with a slash.

- Column I, “AMOUNT OF TOKENS AFTER PENALTY” If you were penalized, you will write down in this column the number corresponding to the amount of tokens you earned (column F) minus the penalty amount. 
Let's do a practice round.

\section{Internal Punishment with Monetary Sanction + Low (High) Penalty Regulation}

We are about to begin the second part of the exercise. This part of the exercise is very similar to the first, the difference being that during the next 10 rounds we are introducing a penalty after the moment when you decide whether to pay the 3 tokens fee to have someone else earnings reduced or not. The target we seek with the penalty is that every group member puts all its 25 tokens into the project.

To encourage that every one puts its 25 tokens into the group project, you will be penalized 1 token (4 tokens) for every token you decide to keep for your self.

I will hand to you a table where the penalties levels are shown according to the amount of tokens that you keep for your self or in other words, those tokens that you did not contribute into the project. <Hand over penalties table>

You will be penalized only if you are audited and you are contributing with less than 25 tokens to project. In other words, you can contribute with less than 25 tokens, but if you are audited, you will have to pay 1 token (4 tokens) for every token you kept for your self. However, it is very difficult to audit every group member every time. Therefore, after you decided whether you pay the fee to reduce someone else earnings, after you got those messages informing you about how many reductions you get, and after you calculated the total amount of earned tokens, we will randomly pick to person to be audited.

To decide who will be audited, we will randomly draw a ballot from a bag containing 5 ballots, once for every group member and respectively labeled.

This implies that in every round, each player has one chance in 5 to be audited. If your ballot is drawn and you put less than 25 tokens into the project you will have to pay the penalty. The result of the audit will be public; this means that the remaining 4 group members will know who is audited and how much this person was putting into the group project.

Only one player will be audited per round. The drawn ballot will be returned to the bag. This means that that in every round, all 5 ballots will be in the bag. This is to say that it is possible to be audited more than once during the exercise, just as it is possible that you are never audited. 
Let's do an example. Let's think that everyone kept 15 tokens and put 10 tokens into the project. Total amount of tokens in the group project was 50, therefore "TOKENS I EARNED FROM THE PROJECT" is 20. And just as we had calculated as wrote in the table, "TOTAL AMOUNT OF TOKENS EARNED IN THIS ROUND BEFORE SENDING A MESSAGE AND THE PENALTY” is 35. Since you kept 15 tokens, this is 15 more than what the rule allowed. Hence, if the ballot with your number is picked, you will have to pay 15 tokens (60 tokens). If your number is not picked, you will not have to pay any penalty. $<$ Take a ballot from the bag. Then, show to every body how the audit is publicly done $>$

Please keep in mind that the ballot draw will be done only after we are done with the steps as we did in the first part, this is, after every player decides whether to pay or not the “reduce earnings" fee and after you got those reductions applied to your earnings, and after you calculated the total amount of earned tokens.

Calculation Sheet $<$ hand over the Calculation Sheet $>$

To the Calculation Sheet we have used so far, we have added 3 new columns. These 3 columns are located after column K “TOKENS I GET AFTER SENDING UNHAPPY FACE MESSAGE.” The new columns are:

- Column L: AUDITED THIS ROUND (YES/NO). If your number was the one picked in the random ballot draw, you will writ YES. If your number was not picked, you will write NO.

- Column M: PENALTY AMOUNT: You will keep track of the tokens you are penalized with when you are audited. If you are audited and were breaking the rule, the assistant will make public announce of how many tokens you were keeping for your self and the respective penalty. The assistant will personally write this amount in your Calculation Sheet.

If your number was not picked, you don't have to pay any penalty regardless of how many tokens you kept. In this case please fill this column with a slash.

- Column N, AMOUNT OF TOKENS AFTER PENALTY If you were penalized, you will write down in this column the number corresponding to the amount of tokens you earned minus the penalty amount.

Let's do a practice round. 